practical use of this novel source of resistance is to transfer chromosome segments containing genes for resistance from the wild species to wheat by the translocation of small chromosome segments using X-radiation. Sears (Brookhaven Symposia in Biology, No. 9, 1956) succeeded in transferring resistance to leaf rust from Aegilops umbellata to wheat, and Elliott ( $J$. Hered., 48, $77 ; 1957$ ) has now accomplished the transference of resistance to the black rust of wheat from Agropyron elongatum (tall wheat grass) to the common bread wheat. Tall wheat grass is a $7 x$ (heptaploid) species. The first step was to cross it with $6 x$ (hexaploid) wheat. After a fow segregating generations, stem resistance was stabilized at the octaploid level. A resistant octaploid was then pollinated by a susceptible wheat, and the hybrid seeds were irradiated in various ways. A single rustresistant wheat-like plant, which was shown to be hexaploid and easily crossed with ordinary wheat, was isolated from the second generation after X-irradiation with a dosage of $18,000 \mathrm{r}$. units. All the sister plants were susceptible except for two weak, sterile grass-like plants. The resistant plant bred true to resistance in the next and subsequent generations. Cytological examination of crosses between the resistant form and a susceptible hexaploid wheat indicated that at least three chromosomal interchanges were involved, and that the presumed translocations were small and probably intercalary. This material cannot, as it stands, serve as a new commercial variety, since it falls short of the desired standards for milling and baking quality. The important thing about it is that it demonstrates a new method of combating a series of pathogens which are a menace to an essential food crop.

\section{Meteor Orbits and Rainfall}

E. G. Bowen has a paper on "A Prediction of a Meteor Orbital Period" in The Observatory $(77,898$; 1957), in which he suggests that meteoritic dust has a nucleating effect which leads to heavy precipitation approximately thirty days after the dust enters the top of the atmosphere. Although the majority of meteorologists have opposed this hypothesis, contending that the results are a chance phenomenon and also that there are no physical grounds for expecting a connexion between meteor showers and rainfall, Bowen emphasizes that if the hypothesis is correct there exists in the meteorological records an impressive collection of information from which, in certain cases, a considerable amount of evidence about past meteor activity might be derived. Bowen refers to a paper of his in J. Met., 13, 142 (1956), which shows that if the daily rainfall of the first five weeks of the year is totalled for about 250 stations in different parts of the world over a period of fifty to sixty years, it does not result in a smooth curve but exhibits distinct peaks on January 12 and 22 and February 1. As is well known, these dates are about thirty days later than the Geminid, Ursid and Quadrantid meteor showers, respectively. While the records from which the curve was compiled included a fair sample of data from the northern hemisphere, the same did not apply to the southern hemisphere; but many more data from the latter have now become available, the samples coming from fifty stations in Australia, fifty in New Zealand, ten in South Africa and ten in the Argentine. From the data from these stations another curve has been drawn and it shows peaks which closely correspond on practically the same dates with those in the previous curve. It is admitted that a sharp difference of opinion exists among meteorologists regarding these peaks, the majority maintaining that a rainfall curve of this type is a smooth horizontal line with chance fluctuations about the mean, but Bowen contends that they have a real significance (see also Nature, 177, 1121 ; 1956).

\section{Plastic Mounts for Biological Display}

IN the issue of the Museums Journal for September, Dr. Blodwen Lloyd, of the Royal College of Science and Technology, Glasgow, describes a method of mounting biological specimens in transparent plastic. This entails sandwiching the specimens between two sheets of plastic, the air being driven out by the application of low heat and pressure. The technique is specially applicable to objects which are virtually two-dimensional, such as herbarium plants, but can also be used for the mounting of specimens in low relief, as, for example, small bones and woody twigs.

\section{The Oliver Bird Trust}

In July 1957 a charitable fund was established with the title of the Oliver Bird. Trust, the Trustees being Mrs. M. A. Pyke, the Hon. Mrs. Burrell and Dr. A. S. Parkes. The Trust has as its object the advancement of knowledge of methods of fertility control with special reference to the promotion and provision of facilities for tests, clinical trials of systemic methods of contraception as they become available, and in the meantime the improvement of locally-acting spermicides. The Trustees will offer for award in each of the next five years a prize of not less than $£ 250$ and an Oliver Bird Medal for laboratory or clinical work bearing on the control of conception. The first prize will be offered early in 1958, and application should be made not later than December 31 . They will also arrange two annual Oliver Bird Lectures : one with the aim of promoting in medical and scientific circles recognition of the importance of investigating fertility control; the other to be sponsored by the Society for the Study of Fertility, dealing with the technical aspects of the problem. The first technical lecture will be given on November 6 in the lecture theatre at University Hospital Medical School at 5 p.m. by Dr. T. Mann on "The Biochemical Basis of Spermicidal Activity". Finally the Trustees will set up a Council for the Investigation of Fertility Control, which will work in conjunction with the Family Planning Association and will be responsible for organizing tests and clinical trials. Further information can be obtained from the office of the Trust at 64 Sloane Street, London, S.W.I.

\section{Advisory Group for Aeronautical Research and Development}

THE seventh general assembly of the Advisory Group for Aeronautical Research and Development of the North Atlantic Treaty Organization will be held on November 25-26 in Washington, D.C. Dr. Theodore von Kármán, chairman of the Advisory Group, will preside over the formal opening of the general assembly at the Shoreham Hotel, Washington, at which Gen. Nathan F. Twining, chairman of the Joint Chiefs of Staff, North Atlantic Treaty Organization, will give an address on the development of air power in the United States. The first session will be devoted 